\title{
IMPROVEMENT STRATEGIES OF JOB PERFORMANCE: A PERSPECTIVE ON NURSING PROFESSION IN VIETNAM
}

\author{
Phuong Van Nguyen ${ }^{1 *}$, Lien Thi Xuan Nguyen ${ }^{2,3}$ and Nhu Huu Thien Nguyen ${ }^{1}$ \\ ${ }^{1}$ International University, Vietnam National University HCMC, Vietnam \\ ${ }^{2}$ Heart Institute HCMC, Vietnam \\ ${ }^{3}$ Van Hien University HCMC, Vietnam
}

\begin{abstract}
As an increase in overloaded general hospitals in Vietnam, nurses are under intensive pressure but receive little opportunities for learning new technical skills and for developing an obvious career path. Meanwhile, nurse performance is essential to quality outcomes of healthcare services. Therefore, this study aims to investigate primary drivers of nurse performance by using the structural equation model approach to analyze a survey of 366 nurses working in four hospitals in Ho Chi Minh City and Bac Lieu province, Vietnam. The results show the facilitating effects of affective commitment and self-leadership on job performance, but not continuance commitment and communication competence. Also, the empirical evidence supports that perceived organizational support and psychological safety indirectly impact job performance through affective commitment. Job resources, however, are insignificantly related to affective commitment. The study indicated that nurses with a high degree of self-leadership and affective commitment to the organization are prone to attain high job performance. Therefore, managers should implement strategies to enhance nurses' conception of self-leadership and affective commitment, which would be an efficient approach to improve quality healthcare services. This study also makes some explanations for the divergence between the previous literature on factors affecting nurse performance and that in Vietnamese hospital context.
\end{abstract}

Keywords: job performance, nurses, affective commitment, self-leadership

\section{Introduction}

In most professions, human resource management has been catching great attention as its direct influence on the prosperity and sustainable development of the organization (Becker and Gerhart, 1996, Rogers and Wright, 1998, Sheehan, 2014). Particularly in the healthcare field, managerial practices are increasingly applied to promote the competency of nurses. According to Lee and Ko (2010), nurses are on the front line of caregiving to patients in partnership with various positions like physicians, medical technologists, and administrative staff. Hence, the performance of nurses is closely associated with services quality and organizational outcomes. The identification of factors boosting nurses' job performance (JP) has become an essential research topic in the field of healthcare in different economic and cultural backgrounds.

Currently, scholars have explored a large number of factors impacting job performance such as work environment, job satisfaction, leadership styles (Kacmar et al. 2009, Platis et al. 2015, Manning, 2016). In this research, we aim to analyze the effect of organizational commitment on raising job performance. Organizational commitment (affective, continuance and normative commitment) is among the most critical elements due to its role in anticipating organizational goals, absenteeism, turnover, and productivity (Wasti, 2003). It is crucial to recognize the positive outcomes of high organizational commitment and to encourage nurses' participation in organizational activities to improve the operational effectiveness (Liou, 2008). Previous studies showed that affective commitment $(\mathrm{AC})$ and normative commitment have a positive interconnection, meaning that they have the same pattern of correlation (Meyer et al. 2002). While the other dimension, continuance commitment 
(CCM), seems to have particular patterns. Hence, this research will place focus only on the significance of affective and continuance commitment.

Furthermore, affective commitment has been found as the strongest predictor of nursing performance (Meyer $e t$ al. 2002, Qaisar et al. 2012). As a result, our study will examine its possible drivers including perceived organizational support (POS), psychological safety (PS), and job resources (JR). In particular, employees' positive feeling at work can be boosted under the environment where they perceive greater organizational support (Lee et al. 2010) and a sense of psychological safety (Kark and Carmeli, 2009). Also, the provision of job resources was proved as an important element to create a positive work setting, which in turn increases employees' affective commitment (Kirk-Brown and Van Dijk, 2016). Although previous studies have confirmed the significant contribution of these factors on raising affective commitment, further investigation in different contexts is still necessary to evaluate the generalization of these findings.

In today hospitals' setting, nurses are holding the major responsibilities for the internal management of patient care. Therefore, self-leadership (SL) should be considered as an essential factor in the construct of job performance. The implication of self-leadership might encourage the ability of self-control and responsibility among nurses, which results in favorable organizational outcomes (Manz, 1983). Prussia et al. (1998) showed that the relationship between self-leadership and performance outcomes is mediated by nurses' self-efficacy. Likewise, Lee and Ko (2010) revealed that self-efficacy is a facilitator of high-quality nursing care. However, few researchers have examined the direct contribution of self-leadership in determining nurse performance.

According to Moreland and Apker (2016), nursing practices involve executing care services to patients on the most frequent basic and also interacting with patients' families and other nursing teams. Moreover, Commission (2012) shows that communication-related problems account for 50\% of confliction among nurses. Taken together, these suggested that the nursing job is highly based on interpersonal communication. Yu and Ko (2017) asserted that a high level of effective communication could reduce such negative events occurred in hospitals, which positively influenced job performance. Thus, it is necessary to improve communication competence $(\mathrm{CCP})$ in the nursing organization.

The purpose of this study is to confirm the significance of nurse performance's drivers in Vietnamese hospitals with distinctive characteristics. The findings enable us to suggest some practical implications to enhance nursing competencies, which in turn helps promote quality and safety in the healthcare community.

\section{Literature Review}

\section{Perceived organizational support, affective commitment, and continuance commitment}

Perceived organizational support refers to the extent to which employees believe that their organizations value their contributions and care for their well-being. According to Shore and Wayne (1993) and El Akremi et al. (2014), under the perception of organizational support, nurses may expect that hospitals would reward their increased effort towards work goals and satisfy their needs of praise and approval. The perceived organizational support can satisfy emotional needs in the workplace such as esteem, approval, and partnership; thus, affective commitment is regarded as its major outcomes (Rhoades et al. 2001). The previous studies also show that the recognition of organizational support is the predictor of continuance commitment, which refers to the cost associated with leaving the organization. The more benefits receive from the current employment, the more valuable organizational membership is; therefore, employees need to keep attached with the organization as they acknowledge the noticeable sacrifice on quitting the job (Shore and Tetrick, 1991, El Akremi et al. 2014). Nurses are more likely to create a bond with their hospitals in the presence of high organizational support because they see a more favorable interrelationship between their contributions and comparable rewards (Shore and Tetrick, 1991). Hence, the following two hypotheses are proposed: 
H1: Perceived organizational support has a significant direct effect on affective commitment.

H2: Perceived organizational support has a significant direct effect on continuance commitment.

\section{Psychological safety and affective commitment}

Psychological safety is the perception where an individual can express his or her self without worrying about negative effects on self-image, status or career (Kahn, 1990). In other words, a work environment characterized by a high level of psychological safety can encourage employees' interpersonal risk-taking. With the perceptions of interpersonal trust and mutual respect, they feel safe to raise questions, seek feedback, report mistakes, or express new ideas without fear of vulnerability (Edmondson, 1999, Kark and Carmeli, 2009). Therefore, psychological safety can foster learning behavior, productive problem resolution as well as positive work experiences which lead to positive organizational outcomes and increased work engagement (Baer and Frese, 2003). Under such a work setting where they can perform their job autonomously with the sense of comfort, nurses tend to get more involved with their organization, thereby being pleased to maintain their membership as they desire. In general, psychological safety is expected to impact the affective commitment of nurses positively, thus coming up with the following hypothesis:

H3: Psychological safety has a significant direct effect on affective commitment.

\section{Job resources and affective commitment}

Job resources refer to those physical, psychological, social, or organizational aspects of the job that are instrumental in reducing job demands, attaining work goals and nourishing personal growth, learning and development (Bakker and Demerouti, 2007, Demerouti et al. 2001). In this research, we assess job resources through two dimensions: job complexity and job autonomy. There is an increasing demand for complete autonomy in the workplace for employees to meet the requirement of more advanced work (Chung-Yan, 2010). Job resources are either intrinsically stimulative as they fulfill the primary desire for autonomy, competence, and belongingness; or extrinsically stimulative as they provide conditions to obtain work success (Schaufeli and Bakker, 2004). Through this prompting process, the provision of valued job resources provokes positive outcomes like work involvement (Demerouti et al. 2001), to which employees are likely to respond with a highly affective commitment to their organization (Kirk-Brown and Van Dijk, 2016). Thus, job resources are hypothetically assumed to have a positive effect on nurses' affective commitment:

H4: Job resources have a significant direct effect on affective commitment.

\section{Affective commitment, continuance commitment, and job performance}

Affective commitment refers to an employee's emotional attachment to, identification with, and involvement in the organization (Meyer and Allen, 1991). Whereas, continuance commitment, the less common but still equally applicable approach, is viewed as the remaining with the organization stemmed from the perceived losses incurred when the employment relationship is discontinued. Committed employees will remain with the current organization as their wish; but for those with high continuance commitment, it is based on their need. Like Tett and Meyer's (1993) findings, some recent studies have indicated that three dimensions of organizational commitment, including affective, continuance and normative commitment, are linked to job performance. Fu and Deshpande (2014) had revealed the significant correlation between organizational commitment and job performance through a study of Chinese employees in an insurance company. Likewise, Khan et al. (2010) found the significance of organizational commitment in determining Pakistan employees' work performance. Hence, the following hypotheses are proposed:

H5: Continuance commitment has a significant direct effect on job performance. 
H6: Affective commitment has a significant direct effect on job performance.

\section{Self-leadership and job performance}

Self-leadership refers to the act of self-influencing to monitor actions and cognitions in a direction that encourages the desired behavior (Manz, 1983, Manz, 1986). In other words, in the presence of autonomy and responsibility, self-leadership appears as an intrinsic motivation to manage oneself to perform must-be-done tasks even if they are naturally motivating or not. It is indicated that nurses' self-leadership and job performance are closely correlated with each other (Chang et al. 2006). Stewart et al. (2011) also suggested that enhanced self-leadership at the individual level is significantly associated with promoting job performance as such employees are more likely to generate higher productivity at work. In addition, self-leadership appears as a facilitator to employees' effective goal-setting process that in turn should lead to the improvement of the whole organization performance (Neck et al. 2003). Therefore, the following hypothesis is proposed:

H7: Self-leadership has a significant direct effect on job performance.

\section{Communication competence and job performance}

Communication competence refers to the ability to align the manner of speaking appropriately through good grammatical and social knowledge. Communication competence, one of the valuable resources, is expected to foster job performance among nurses in healthcare organizations (Bae, 2008, Im et al. 2012, Park et al. 2015). Kang and $\mathrm{Yu}$ (2016) reported that in the presence of communication competence, the correlation between selfleadership and job performance seemed to be more strengthened. Previous studies also found that employees equipped with adequate training to build up communication skills would display more positive outcomes (i.e., reduced anger, decreased emotional stress, improved mental wellness, and low level of burnout) (Swain and Gale, 2014). In addition, communication is reported as the most difficult task in the clinical setting, indicating the necessity of ensuring that adequate strategies are implemented to boost nurses' communication ability (Park and Lee, 2003). Accordingly, the following hypothesis is proposed:

H8: Communication competence has a significant direct effect on job performance.

\section{Research Methodology}

\section{Measurement}

To measure the latent variables observed in this study, we construct the measurement scale which contains 36 items with reference to the scales developed in previous researches. First, job resources are assessed through the one-item Decision Authority scale and two-item Skill Discretion scale from Karasek Jr (1979), which examines its two dimensions: job autonomy and job complexity respectively. Then, the three-item scale is adopted from Baer and Frese (2003) to assess psychological safety. This scale evaluates nurses' perceptions of safety and mutual respect in working place. To measure perceived organizational support, we use five items from Eisenberger et al. (1986) scale which investigates whether nurses acknowledge the assistance from their hospitals. Next, affective commitment with five items and continuance commitment with three items are adopted from Tett and Meyer (1993). The four-item scale developed by Houghton and Neck (2002) is applied to measure self-leadership among nurses, which examines the ability to manage oneself towards work goals. The communication competence measure is based on the measurement of Canary and Spitzberg (1987), consisting of four items which evaluate the success in nurses' workplace interaction. Finally, job performance is assessed through a nine-item scale proposed by Ko et al. (2007), which investigates its two subscales of competency (the first six items) and attitude (the last three items). A five-point Likert scale ( $1=$ strongly disagree, $5=$ strongly agree) is used to evaluate respondents' extent of agreement with each statement on the questionnaire. 


\section{Questionnaire design}

According to Green (1991), the minimum sample size is determined by the formula $8 * m+50$, where $m$ is the number of measurement items. In this study, the survey spreads out over 366 participants so that it sufficiently satisfies the requirement corresponding to 36 items. The questionnaire is designed into two main sections, which are (1) demographic characteristics, including respondents' name, gender, age, number of working year in healthcare field, number of working year in the current organization, number of organizations that they have been worked for; and next (2) 36 items measuring eight latent variables in the hypothetical model. Besides, for best fitting in Vietnam context, all items in the questionnaire are translated into Vietnamese language and partly adjusted for respondents' better understanding.

\section{Data collection}

The survey is conducted in Ho Chi Minh City and Bac Lieu Province, Vietnam by a paper-based questionnaire administered directly to participants. There are two phases in data collecting procedure, including pilot test and official survey. First, the pilot test with a sample size of 36 nurses is carried out to evaluate the measurement scale before spreading to a larger scale. After being adjusted based on the pilot test's results, the final questionnaires are distributed to the nursing staffs of four hospitals. After the deletion of invalid questionnaires, the data extracted from 366 valid observations are used in the final analysis.

\section{Results}

\section{Demographic characteristics}

Table 1 indicates the demographic data of 366 respondents. Most of them are women, and the majority of respondents are under 40 years old $(78.1 \%)$. In addition, their experience in the nursing industry varies from less to more than eight years, with the rate at $50.3 \%$ and $49.7 \%$, respectively. Most of them have served their current hospitals for under 20 years (nearly $91.8 \%$ ), and the number of hospitals for which they have worked is mostly under 2 (at $95.9 \%)$.

Table 1 Demographic characteristics.

\begin{tabular}{lcc}
\hline Characteristics & Number $(\mathrm{N}=366)$ & Percentage \\
\hline Gender & 150 & $41.0 \%$ \\
Male & 216 & $59.0 \%$ \\
Female & & \\
\hline Age & 286 & $78.1 \%$ \\
$21-40$ & 80 & $21.9 \%$ \\
Above 40 & & \\
\hline Experience & 184 & $50.3 \%$ \\
1 - 8 years & 182 & $49.7 \%$ \\
Above eight years & & \\
\hline Number of working years in & & $91.8 \%$ \\
the current hospital & 336 & $8.2 \%$ \\
Under 20 years & 30 & \\
Above 20 years & & $95.9 \%$ \\
\hline Number of hospitals & 351 & $4.1 \%$ \\
Under two hospitals & 15 & \\
Above two hospitals &
\end{tabular}




\section{Reliability analysis}

Exploratory Factor Analysis (EFA) is carried out to verify the underlying relationships among measured variables (i.e., whether a set of variables consistently load on the same factor based on strong correlations). First, the coefficient of Cronbach's alpha is computed for each factor to evaluate the internal consistency of the measurement items. According to Hair et al. (1998), the Cronbach's alpha value, which ranges between 0 and 1 , reveals better reliability among items if it is relatively higher. More specifically, the value of around 0.9 is considered as excellent, around 0.8 as very good, from 0.6 to 0.7 as adequate and below 0.5 as unreliable. In this study, all measured variables present good values of Cronbach's alpha which are nearly or above 0.8 , except for JR valuing at 0.637 (see Table 2). Nevertheless, it is suggested that the value over 0.6 is also acceptable in exploratory research (Fornell and Larcker, 1981).

The KMO measure (0.805) satisfies the recommended acceptable level which must be higher than 0.5. Barlett's Test of Sphericity, Sig. (0.000) is less than 0.05 and total variance explained (69.836\%) is larger than 50\%, which is within the recommended acceptable level. According to Hair et al. (1998), observed variables are considered valid when their factor loadings are over 0.5 , and there are no major cross-loadings between factors (the difference between the loadings should be more than 0.3). In this study, most items have significant factor loadings, which are illustrated in Table 2. However, the two items JP6 and JP7 are removed because of major cross-loadings. JR1 is also erased as its loading is considerably lower than 0.5, while JR2 (factor loading is $0.474)$ is still acceptable since it is very close to the requirement.

\section{Confirmatory factor analysis}

The next step is to validate the measurement model through confirmatory factor analysis (CFA). The acceptable level for Composite Reliability (CR) and Average Variance Extracted (AVE) is 0.7 and 0.5 respectively as recommended by Hair et al. (1998). While the values of most items are acceptable, we need to eliminate SL2 to better its value (see Table 3 ).

In addition, a measurement model with high values of model fit indices is suggested to present a higher level of goodness-of-fit. These indices (shown in Table 4) are the normalized chi-square, root mean square error of approximation, goodness-of-fit index, incremental index of fit, and comparative fit index. Most of the model fit indices exceed the requirement of acceptance, except for GFI is less than but very close to the standard, indicating that the measurement model in this research obtains a considerable goodness-of-fit.

\section{Structural equation modeling and Hypothesis testing}

Structural equation modeling (SEM) is an approach to assess the overall fit of the structural model by using Maximum likelihood estimate which is conducted in the software AMOS 20.0. All the fit indices observed in this analysis is measured based on the same reference standards in CFA. As shown in Table 4, most indices are within the range of acceptance, while some nearly satisfy the requirement.

Moreover, the hypothesis will be accepted if its path coefficient is presented as statistical significance. The summary of the estimated standardized path coefficients is presented in Table 5. At the 0.05 level of confidence, most of the path coefficients are positively significant, except for those from JR to AC, CCM to JP, and CCP to JP. As observed from the result, POS has a significant impact on both CCM and AC. Thus, hypothesis $\mathrm{H} 1$ and $\mathrm{H} 2$ are supported. The impact of PS on AC is statistically significant, indicating that $\mathrm{H} 3$ is supported; while $\mathrm{H} 4$ is not accepted because of the insignificant coefficient from JR to AC. Moreover, the result shows that both AC and SL are significantly positively related to JP, but there is no significant impact of CCM and CCP on JP. Hence, hypothesis $\mathrm{H} 6$ and $\mathrm{H} 7$ are accepted, while $\mathrm{H} 5$ and $\mathrm{H} 8$ are rejected. 
Proceeding of the $4^{\text {th }}$ International Conference on Public Health, Vol. 4, 2018, pp. 60-72

Table 2 Factor loadings in EFA, CFA, and Cronbach's Alpha.

\begin{tabular}{|c|c|c|c|c|}
\hline Variables & $\begin{array}{l}\text { Measurement } \\
\text { Items }\end{array}$ & EFA & CFA & $\begin{array}{l}\text { Cronbach's } \\
\text { Alpha }\end{array}$ \\
\hline \multirow{5}{*}{$\begin{array}{l}\text { Perceived } \\
\text { organizational support } \\
\text { (POS) }\end{array}$} & POS1 & 0.712 & 0.750 & \multirow[t]{5}{*}{0.871} \\
\hline & POS2 & 0.685 & 0.734 & \\
\hline & POS3 & 0.791 & 0.827 & \\
\hline & POS4 & 0.757 & 0.780 & \\
\hline & POS5 & 0.685 & 0.681 & \\
\hline \multirow{5}{*}{$\begin{array}{l}\text { Affective commitment } \\
\text { (AC) }\end{array}$} & $\mathrm{AC} 1$ & 0.734 & 0.785 & \multirow[t]{5}{*}{0.877} \\
\hline & $\mathrm{AC} 2$ & 0.749 & 0.780 & \\
\hline & $\mathrm{AC} 3$ & 0.771 & 0.839 & \\
\hline & $\mathrm{AC} 4$ & 0.669 & 0.710 & \\
\hline & AC5 & 0.678 & 0.711 & \\
\hline \multirow{3}{*}{$\begin{array}{l}\text { Continuance } \\
\text { commitment (CCM) }\end{array}$} & CCM1 & 0.655 & 0.697 & \multirow[t]{3}{*}{0.801} \\
\hline & CCM2 & 0.734 & 0.835 & \\
\hline & CCM3 & 0.722 & 0.734 & \\
\hline \multirow{3}{*}{$\begin{array}{l}\text { Psychological safety } \\
\text { (PS) }\end{array}$} & PS1 & 0.786 & 0.858 & \multirow[t]{3}{*}{0.789} \\
\hline & PS2 & 0.695 & 0.756 & \\
\hline & PS3 & 0.637 & 0.667 & \\
\hline \multirow[t]{2}{*}{ Job resources (JR) } & JR2 & 0.474 & 0.479 & \multirow[t]{2}{*}{0.637} \\
\hline & JR3 & 0.977 & 1.014 & \\
\hline \multirow[t]{3}{*}{ Self-leadership (SL) } & SL1 & 0.629 & 0.601 & \multirow[t]{3}{*}{0.781} \\
\hline & SL3 & 0.780 & 0.880 & \\
\hline & SL4 & 0.756 & 0.738 & \\
\hline \multirow{4}{*}{$\begin{array}{l}\text { Communication } \\
\text { competence (CCP) }\end{array}$} & CCP1 & 0.641 & 0.662 & \multirow[t]{4}{*}{0.826} \\
\hline & $\mathrm{CCP} 2$ & 0.802 & 0.837 & \\
\hline & CCP3 & 0.773 & 0.788 & \\
\hline & CCP4 & 0.655 & 0.666 & \\
\hline Job performance (JP) & JP1 & 0.692 & 0.727 & \multirow[t]{5}{*}{0.866} \\
\hline \multirow[t]{4}{*}{ Competence } & $\mathrm{JP} 2$ & 0.684 & 0.710 & \\
\hline & JP3 & 0.780 & 0.766 & \\
\hline & JP4 & 0.840 & 0.877 & \\
\hline & JP5 & 0.694 & 0.673 & \\
\hline \multirow{2}{*}{$\begin{array}{l}\text { Job performance }(\mathrm{JP}) \\
\text { Attitude }\end{array}$} & JP8 & 0.611 & 0.632 & \multirow[t]{2}{*}{0.756} \\
\hline & JP9 & 0.938 & 1.034 & \\
\hline
\end{tabular}

Table 3 Composite Reliability and Average Variance Extracted.

\begin{tabular}{lcc}
\hline Variable & CR & AVE \\
\hline Perceived organizational support (POS) & 0.872 & 0.577 \\
Affective commitment (AC) & 0.879 & 0.594 \\
Continuance commitment (CCM) & 0.816 & 0.597 \\
Psychological safety (PS) & 0.801 & 0.573 \\
Job resources (JR) & 0.673 & 0.514 \\
Self-leadership (SL) & 0.786 & 0.554 \\
Communication competence (CCP) & 0.830 & 0.552 \\
Job performance (JP) - Competence & 0.830 & 0.710 \\
Job performance (JP) - Attitude & 0.866 & 0.566 \\
\hline
\end{tabular}


Table 4 Model fit indices in CFA and SEM.

\begin{tabular}{lcccc}
\hline $\begin{array}{l}\text { Model fit } \\
\text { indices }\end{array}$ & Thresholds & CFA & SEM & References \\
\hline$\chi 2 /$ df & $1-3$ & 2.215 & 2.377 & Barbara (2001) \\
RMSEA & $<0.08$ & 0.058 & 0.061 & Bentler and Bonett (1980) \\
GFI & $\geq 0.90$ & 0.863 & & Tabachnick et al. $(2001)$ \\
IFI & $\geq 0.90$ & 0.904 & 0.887 & Bentler and Bonett (1980) \\
CFI & $\geq 0.90$ & 0.903 & 0.886 & Bentler and Bonett (1980) \\
\hline
\end{tabular}

Table 5 Results of the model in SEM.

\begin{tabular}{llcccc}
\hline Hypothesis & Path & $\begin{array}{c}\text { Path } \\
\text { coefficient }\end{array}$ & S.E. & C.R. & P \\
\hline H1 & CCM $\leftarrow$ POS & 0.304 & 0.053 & 5.709 & $* * *$ \\
H2 & AC $\leftarrow$ POS & 0.270 & 0.055 & 4.936 & $* * *$ \\
H3 & AC $\leftarrow$ PS & 0.275 & 0.072 & 3.806 & $* * *$ \\
H4 & AC $\leftarrow$ JR & 0.137 & 0.081 & 1.684 & 0.092 \\
H5 & JP $\leftarrow$ CCM & 0.014 & 0.037 & 0.388 & 0.698 \\
H6 & JP $\leftarrow$ AC & 0.089 & 0.039 & 2.284 & 0.022 \\
H7 & JP $\leftarrow$ SL & 0.216 & 0.050 & 4.294 & $* * *$ \\
H8 & JP $\leftarrow$ CCP & 0.061 & 0.041 & 0.133 & 0.133 \\
\hline
\end{tabular}

*** Statistically significant at the 0.001 level of confidence.

In this study, it is found that the effect of SL on JP (path coefficient is 0.216 ) is more considerable than other three predictors including CCM, AC, and CCP $(0.014,0.089$, and 0.061 , respectively). The path coefficient of PS to AC (0.275) reveals its better contribution compared to that of POS (0.270) and JR (0.137).

\section{Discussion}

The results indicate that affective commitment is significantly related to job performance among nurses, which is consistent with previous studies of Jaramillo et al. (2005), Fu and Deshpande (2014), and Khan et al. (2010). This implies that when nurses feel a greater sense of emotional connection with their hospital, they will put more concern in the organization's welfare, which intrinsically motivates themselves to generate higher performance. Also, the findings of our study reveal the mediating effect of perceived organizational support on the correlation between affective commitment and job performance due to the significant path coefficients of POS to AC and AC to JP. In line with Darolia et al. (2010), the care of employees' well-being and the tendency to reward increased efforts from the organization would facilitate nurses' affective bond to their hospitals, which make them feel an obligation to contribute more for the collective benefits. Comparatively, psychological safety is observed as a more significant mediator between affective commitment and job performance. Under the sense of safety, comfort and mutual respect, positive work experiences and work engagement are easily witnessed from those whose performance is affected by positive attitude and behavior towards the organizational optimization (Kirk-Brown and Van Dijk, 2016). For example, in the psychologically safe environment where nurses can freely make contributions to the group discussion on treatment methods for patients, they are inclined to feel strong involvement with the job and then generate higher productivity. With the aim of promoting job performance through enhanced affective commitment, managerial strategies like anti-discrimination approach and the principles of social inclusion (being included within a group) are necessarily implemented to reduce psychologically and socially harmful manners such as bullying or harassment (Shain, 2009). 
The results, however, show that the provision of job resources (job autonomy and job complexity) does not necessarily induce a higher level of affective commitment. This is incompatible with existing findings that job resources can reinforce employees' affective attachment with organizations (Salanova et al. 2005). This insignificance of job resources might come from the particular characteristics held in Vietnam, which considers nursing as a professional career that requires the advanced level of knowledge or expertise rather than creative works. Indeed, nurses are required to follow the guidelines for proper documentation and appointments from the physician in any given task (Frank-Stromborg et al. 2001). Therefore, it might not be a bothersome constraint to nurses when they must adhere to the exacting standards to provide care services, indicating a minimal demand for autonomy in the workplace. However, the level of nursing training quality and the scope of practice in the future will observe many changes. Nurses will be able to take in in-depth training programs on a local and global scale, thus creating incentives for them to contribute valuable ideas as well as participate directly in the process of improving nursing service quality. This warrants further investigation into the granting of job autonomy, the recognition of the nurses' role, and their effect on nursing performance in Vietnam. In addition, future studies examining other dimensions of job resources in various hospital scales are also necessary.

This study reveals that continuance commitment emerges as an insignificant driver of job performance, which aligns with Gong et al. (2009) study that although enhanced performance may be explored in the organization characterized by high level of affective commitment, it may not when it comes to continuance commitment. This is somewhat opposed to the study of Fu and Deshpande (2014) who showed that organizational commitment through its three dimensions (affective, continuance and normative) is a major predictor of job performance among Chinese employees. Meanwhile, Schrock et al. (2016) addressed an adverse effect of continuance commitment on job performance. They found continuance commitment weakening the positive association between affective commitment and job performance. In the Vietnamese healthcare industry, the insignificance of continuance commitment may result from the inadequate enthusiasm for the job. This means that nurses with high continuance commitment may perceive the maintenance with their organization simply as a need because they want to avoid the side bets associated with leaving the current job. For these individuals, the likelihood of engaging in supportive behaviors towards organizational goals is uncertain (Shore and Wayne, 1993). In general, there exists a disparity in these findings; consequently, future studies should be conducted to clarify the role of continuance commitment in determining job performance and other possible drivers in different economic, cultural and occupational backgrounds.

The findings of our study show that the facilitating effect of communication competence on job performance does not exist. This is antithetical to previous researches announcing communication competence as the important driver of job performance (Im et al. 2012, Yu and Ko, 2017). They pointed out that nursing performance is notably promoted as a consequence of the improved interpersonal competence. These findings imply that the degree of communication competence's influence may vary by job characteristics among different work settings. Indeed, in today's hospitals, every department requires its employees to meet specific skills. Nursing staffs in Clinical or Internal Medicine Department mainly interact with patients and their guardian day by day. Thus they are expected to be able to communicate well because obtaining communication capacity are inclined to facilitate their performance. However, it does not necessarily mean that nurses who acquire the average or lower level of communicating skills are constrained away from the advancement in work outcome. For example, nurses working in Department of Surgery, Department of Anesthesiology, or Department of Resuscitation, are not obliged to be excellent at cooperation because of their distinctive occupational characteristics which are not mainly based on direct intercommunication with patients. This infers that their evolved performance might derive from other potential variables such as their increased effort to boost technical skills. Therefore, it is not so startling that the development of communication competence may bring about minor improvement in Vietnamese nursing services.

Extracted from the results, it is observed that self-leadership is the significant predictor that makes the greatest contribution to the enhancement of nursing performance. These findings support the study of Chang et al. 
(2006) who reveals that job performance can be improved through the appropriate programs boosting selfleadership. Of particular importance is what should be implemented to improve self-leadership among nurses; thereby, the provision of various training programs and education that pursue such improvement is necessary. In particular, the knowledge acquired from courses investigating self-assertion and self-expression could be practiced to efficiently deal with typical and specific cases in daily tasks (Yu and Ko, 2017). Besides, it also calls for the organization's interest in forming a work setting that inspires nurses to present their innovative and active self-leadership. Additionally, the potential approach to horn nurses' capacity of self-leading is to regularly encourage their straightforward self-reflection on previous experiences and their openness to adapt in the future. The method of reviewing with a trusted partner or mentor and getting appropriate feedback from parties might work here (Angelucci, 2005).

\section{Conclusion}

As an important element related to a hospital's effectiveness and reliability, service quality assessed through nurses' job performance has been examined in many previous studies. This study focuses on exploring determining factors in improving job performance among nurses in Vietnamese hospitals. The results show that affective commitment and self-leadership are the direct and significant predictors of job performance, but not continuance commitment and communication competence. It also reveals that perceived organizational support and psychological safety are indirectly related to job performance under the mediating role of affective commitment. Furthermore, improvement in self-leadership is proved as a more efficient method to raise nursing performance because of its better influence than that of affective commitment.

These findings suggest some useful procedures to cultivate nurses with required competence to provide highquality care services. Firstly, approaches targeting a work setting that gives employees a sense of inclusion, safety, and interpersonal respect should be pursued. Besides, if nurse managers apply proper rewarding policies to praise nurses' increased efforts and take good care of their development, it is possible to reinforce nurse performance through a strong affective bond with the organization. Secondly, the managerial approach should aim to strengthen nurses' ability in self-leadership. Results-Based Management style is suggested as an advanced method which sets specific goals and tightly keeps pace with the work to attain desired outcomes. After that, the process of reviewing on both individual and collective scale is necessary to strive for improvement in later performance. Additionally, various education programs and training activities tailored to each nursing department's characteristics should be provided to raise the awareness of the necessity to stimulate productivity through self-leadership. In short, the expected outcomes of these programs would be the delivery of proficient and reliable care services by qualified nurses in the environment with high professional ethics.

Our study also makes some explanations for the divergence between previous literature on factors affecting nurses performance and that in the Vietnam context. However, regarding the generalizability of the findings, future researches need to be conducted to investigate other potential job performance's predictors in various hospital size and characteristics. Another limitation of this study is that the possible effect of the disparity between countries on the quality of health care services is not considered. Hence, an international research comparison would be worthwhile.

\section{References}

El Akremi, A., Colaianni, G., Portoghese, I., Galletta, M. and Battistelli, A. (2014), "How organizational support impacts affective commitment and turnover among Italian nurses: A multilevel mediation model", The International Journal of Human Resource Management, Taylor \& Francis, Vol. 25 No. 9, pp. 1185-1207.

Angelucci, P.A. (2005), "For leadership effectiveness, look inside”, Nursing Management, LWW, Vol. 36 No. 11 , pp. 12-15.

Bae, J.Y. (2008), "The relationships among the level of communication competence, the types of communication, and the level of nursing performance", Unpublished Master's Thesis, Kosin University, Busan. 
Baer, M. and Frese, M. (2003), "Innovation is not enough: Climates for initiative and psychological safety, process innovations, and firm performance", Journal of Organizational Behavior: The International Journal of Industrial, Occupational and Organizational Psychology and Behavior, Wiley Online Library, Vol. 24 No. 1, pp. 45-68.

Bakker, A.B. and Demerouti, E. (2007), “The job demands-resources model: State of the art", Journal of Managerial Psychology, Emerald Group Publishing Limited, Vol. 22 No. 3, pp. 309-328.

Barbara, M.B. (2001), "Structural equation modeling with AMOS: Basic concepts, applications, and programming".

Becker, B. and Gerhart, B. (1996), "The impact of human resource management on organizational performance: Progress and prospects", Academy of Management Journal, Academy of Management Briarcliff Manor, NY 10510, Vol. 39 No. 4, pp. 779-801.

Bentler, P.M. and Bonett, D.G. (1980), "Significance tests and goodness of fit in the analysis of covariance structures", Psychological Bulletin, available at:https://doi.org/10.1037/0033-2909.88.3.588.

Canary, D.J. and Spitzberg, B.H. (1987), “Appropriateness and effectiveness perceptions of conflict strategies", Human Communication Research, Wiley Online Library, Vol. 14 No. 1, pp. 93-120.

Chang, S.-O., Cho, K.-H., Kim, I.-A., Lee, S.-J. and Seomun, G. (2006), "The relation between self-leadership and outcome of nursing practice", Journal of Korean Academy of Nursing Administration, Korean Academy of Nursing Administration, Vol. 12 No. 1, pp. 151-158.

Chung-Yan, G.A. (2010), "The nonlinear effects of job complexity and autonomy on job satisfaction, turnover, and psychological well-being.", Journal of Occupational Health Psychology, Educational Publishing Foundation, Vol. 15 No. 3, p. 237.

Commission, J. (2012), “Joint Commission Center for Transforming Healthcare”, Joint Commission Resources Hot Topics in Health Care-Transitions of Care: The Need for a More Effective Approach to Continuing Patient Care Http://Www. Jointcommission.Org/Assets/1/18/Hot_Topics_Transitions_of_Care.Pdf. Updated.

Darolia, C.R., Kumari, P. and Darolia, S. (2010), "Perceived organizational support, work motivation, and organizational commitment as determinants of job performance", Journal of the Indian Academy of Applied Psychology, Vol. 36 No. 1, pp. 69-78.

Demerouti, E., Bakker, A.B., Nachreiner, F. and Schaufeli, W.B. (2001), "The job demands-resources model of burnout.", Journal of Applied Psychology, US: American Psychological Association, Vol. 86 No. 3, p. 499.

Edmondson, A. (1999), "Psychological safety and learning behavior in work teams", Administrative Science Quarterly, Sage Publications, Vol. 44 No. 2, pp. 350-383.

Eisenberger, R., Huntington, R., Hutchison, S. and Sowa, D. (1986), "Perceived organizational support.", Journal of Applied Psychology, American Psychological Association, Vol. 71 No. 3, p. 500.

Fornell, C. and Larcker, D.F. (1981), "Evaluating structural equation models with unobservable variables and measurement error", Journal of Marketing Research, JSTOR, pp. 39-50.

Frank-Stromborg, M., Christensen, A. and Do, D.E. (2001), "Nurse documentation: not done or worse, done the wrong way--Part II.”, Oncology Nursing Forum, Vol. 28.

Fu, W. and Deshpande, S.P. (2014), "The Impact of Caring Climate, Job Satisfaction, and Organizational Commitment on Job Performance of Employees in a China's Insurance Company", Journal of Business Ethics, Vol. 124 No. 2, pp. 339-349.

Gong, Y., Law, K.S., Chang, S. and Xin, K.R. (2009), "Human resources management and firm performance: The differential role of managerial affective and continuance commitment.", Journal of Applied Psychology, American Psychological Association, Vol. 94 No. 1, p. 263.

Green, S.B. (1991), "How many subjects does it take to do a regression analysis", Multivariate Behavioral Research, Taylor \& Francis, Vol. 26 No. 3, pp. 499-510.

Hair, J.F., Anderson, R.E., Tatham, R.L. and Black, W.C. (1998), Multivariate Data Analysis, International Journal of Pharmaceutics, available at:https://doi.org/10.1016/j.ijpharm.2011.02.019.

Houghton, J.D. and Neck, C.P. (2002), "The revised self-leadership questionnaire: Testing a hierarchical factor structure for self-leadership", Journal of Managerial Psychology, MCB UP Ltd, Vol. 17 No. 8, pp. 672-691.

Im, S.I., Park, J. and Kim, H.S. (2012), “The Effects of Nurses Communication and Self-Leadership on Nursing Performance", Korean Journal of Occupational Health Nursing, Korean Academic Society of Occupational 
Helth Nursing, Vol. 21 No. 3, pp. 274-282.

Jaramillo, F., Mulki, J.P. and Marshall, G.W. (2005), "A meta-analysis of the relationship between organizational commitment and salesperson job performance: 25 years of research", Journal of Business Research, Elsevier, Vol. 58 No. 6, pp. 705-714.

Kacmar, K.M., Collins, B.J., Harris, K.J. and Judge, T.A. (2009), “Core self-evaluations and job performance: the role of the perceived work environment.", Journal of Applied Psychology, American Psychological Association, Vol. 94 No. 6, p. 1572.

Kahn, W.A. (1990), "Psychological conditions of personal engagement and disengagement at work", Academy of Management Journal, Academy of Management Briarcliff Manor, NY 10510, Vol. 33 No. 4, pp. $692-724$.

Kang, K.H. and Yu, S. (2016), “Analysis of students experience related of nursing management clinical practice: Text network analysis method", Journal of Korean Academy of Nursing Administration, Vol. 22 No. 1, pp. 8090 .

Karasek Jr, R.A. (1979), “Job demands, job decision latitude, and mental strain: Implications for job redesign”, Administrative Science Quarterly, JSTOR, pp. 285-308.

Kark, R. and Carmeli, A. (2009), "Alive and creating: The mediating role of vitality and aliveness in the relationship between psychological safety and creative work involvement", Journal of Organizational Behavior: The International Journal of Industrial, Occupational and Organizational Psychology and Behavior, Wiley Online Library, Vol. 30 No. 6, pp. 785-804.

Khan, M.R., Ziauddin, J.F. and Ramay, M.I. (2010), “The impacts of organizational commitment on employee job performance”, European Journal of Social Sciences, Vol. 15 No. 3, pp. 292-298.

Kirk-Brown, A. and Van Dijk, P. (2016), “An examination of the role of psychological safety in the relationship between job resources, affective commitment and turnover intentions of Australian employees with chronic illness", International Journal of Human Resource Management, Vol. 27 No. 14, pp. 1626-1641.

Ko, Y.K., Lee, T.W. and Lim, J.Y. (2007), "Development of a performance measurement scale for hospital nurses", Journal of Korean Academy of Nursing, Vol. 37 No. 3, pp. 286-294.

Lee, T.-R., Chen, S.-Y., Wang, S.-H. and Dadura, A. (2010), "The relationship between spiritual management and determinants of turnover intention", European Business Review, Emerald Group Publishing Limited, Vol. 22 No. 1, pp. 102-116.

Lee, T.W. and Ko, Y.K. (2010), "Effects of self-efficacy, affectivity and collective efficacy on nursing performance of hospital nurses", Journal of Advanced Nursing, Wiley Online Library, Vol. 66 No. 4, pp. 839848.

Liou, S. (2008), "An analysis of the concept of organizational commitment", Nursing Fórum, Wiley Online Library, Vol. 43 No. 3, pp. 116-125.

Manning, J. (2016), “The influence of nurse manager leadership style on staff nurse work engagement”, Journal of Nursing Administration, LWW, Vol. 46 No. 9, pp. 438-443.

Manz, C.C. (1983), The Art of Self-Leadership: Strategies for Personal Effectiveness in Your Life and Work, Prentice-Hall.

Manz, C.C. (1986), "Self-leadership: Toward an expanded theory of self-influence processes in organizations", Academy of Management Review, Academy of Management Briarcliff Manor, NY 10510, Vol. 11 No. 3, pp. 585-600.

Meyer, J.P. and Allen, N.J. (1991), "A three-component conceptualization of organizational commitment", Human Resource Management Review, Elsevier, Vol. 1 No. 1, pp. 61-89.

Meyer, J.P., Stanley, D.J., Herscovitch, L. and Topolnytsky, L. (2002), “Affective, continuance, and normative commitment to the organization: A meta-analysis of antecedents, correlates, and consequences", Journal of Vocational Behavior, Elsevier, Vol. 61 No. 1, pp. 20-52.

Moreland, J.J. and Apker, J. (2016), "Conflict and stress in hospital nursing: Improving communicative responses to enduring professional challenges", Health Communication, Taylor \& Francis, Vol. 31 No. 7, pp. 815-823.

Neck, C.P., Nouri, H. and Godwin, J.L. (2003), "How self-leadership affects the goal-setting process", Human Resource Management Review, Elsevier, Vol. 13 No. 4, pp. 691-707.

Park, K.M. and Lee, B.S. (2003), "Relations between the types of communication and, job satisfaction and 
nursing performance in staff nurses", Journal of Korean Public Health Nursing, Korean Society of public Health Nursing, Vol. 17 No. 2, pp. 317-332.

Park, N.K., Lee, H., Lee, T. and Park, J.S. (2015), “Correlations among emotional labor, servant leadership, and communication competence in hospital nurses", Korean Journal of Occupational Health Nursing, KoreaMed, Vol. 24 No. 2, pp. 57-66.

Platis, C., Reklitis, P. and Zimeras, S. (2015), "Relation between job satisfaction and job performance in healthcare services", Procedia-Social and Behavioral Sciences, Elsevier, Vol. 175, pp. 480-487.

Prussia, G.E., Anderson, J.S. and Manz, C.C. (1998), "Self-leadership and performance outcomes: the mediating influence of self-efficacy", Journal of Organizational Behavior: The International Journal of Industrial, Occupational and Organizational Psychology and Behavior, Wiley Online Library, Vol. 19 No. 5, pp. 523-538.

Qaisar, M.U., Rehman, M.S. and Suffyan, M. (2012), "Exploring effects of organizational commitment on employee performance: Implications for human resource strategy", Interdisciplinary Journal of Contemporary Research in Business, Vol. 3 No. 11, pp. 248-255.

Rhoades, L., Eisenberger, R. and Armeli, S. (2001), "Affective commitment to the organization: The contribution of perceived organizational support.", Journal of Applied Psychology, American Psychological Association, Vol. 86 No. 5, p. 825.

Rogers, E.W. and Wright, P.M. (1998), "Measuring organizational performance in strategic human resource management: Problems, prospects and performance information markets", Human Resource Management Review, Elsevier, Vol. 8 No. 3, pp. 311-331.

Salanova, M., Agut, S. and Peiró, J.M. (2005), "Linking organizational resources and work engagement to employee performance and customer loyalty: the mediation of service climate.", Journal of Applied Psychology, American Psychological Association, Vol. 90 No. 6, p. 1217.

Schaufeli, W.B. and Bakker, A.B. (2004), "Job demands, job resources, and their relationship with burnout and engagement: A multi-sample study", Journal of Organizational Behavior: The International Journal of Industrial, Occupational and Organizational Psychology and Behavior, Wiley Online Library, Vol. 25 No. 3, pp. 293-315.

Schrock, W.A., Hughes, D.E., Fu, F.Q., Richards, K.A. and Jones, E. (2016), "Better together: trait competitiveness and competitive psychological climate as antecedents of salesperson organizational commitment and sales performance", Marketing Letters, Springer, Vol. 27 No. 2, pp. 351-360.

Shain, M. (2009), "Psychological safety at work: Emergence of a corporate and social agenda in Canada", International Journal of Mental Health Promotion, Taylor \& Francis, Vol. 11 No. 3, pp. 42-48.

Sheehan, M. (2014), "Human resource management and performance: Evidence from small and medium-sized firms", International Small Business Journal, Sage Publications Sage UK: London, England, Vol. 32 No. 5, pp. 545-570.

Shore, L.M. and Tetrick, L.E. (1991), “A construct validity study of the survey of perceived organizational support.”, Journal of Applied Psychology, American Psychological Association, Vol. 76 No. 5, p. 637.

Shore, L.M. and Wayne, S.J. (1993), "Commitment and employee behavior: Comparison of affective commitment and continuance commitment with perceived organizational support.", Journal of Applied Psychology, American Psychological Association, Vol. 78 No. 5, p. 774.

Stewart, G.L., Courtright, S.H. and Manz, C.C. (2011), "Self-leadership: A multilevel review", Journal of Management, Sage Publications Sage CA: Los Angeles, CA, Vol. 37 No. 1, pp. 185-222.

Swain, N. and Gale, C. (2014), "A communication skills intervention for community healthcare workers reduces perceived patient aggression: A pretest-postest study”, International Journal of Nursing Studies, Elsevier, Vol. 51 No. 9, pp. 1241-1245.

Tabachnick, B., Fidell, L. and Osterlind, S. (2001), "Using multivariate statistics”, Allyn and Bacon Boston.

Tett, R.P. and Meyer, J.P. (1993), "Job satisfaction, organizational commitment, turnover intention, and turnover: path analyses based on meta-analytic findings", Personnel Psychology, Wiley Online Library, Vol. 46 No. 2, pp. 259-293.

Wasti, S.A. (2003), "Organizational commitment, turnover intentions and the influence of cultural values", Journal of Occupational and Organizational Psychology, Wiley Online Library, Vol. 76 No. 3, pp. 303-321.

Yu, S. and Ko, Y. (2017), "Communication competency as a mediator in the self-leadership to job performance relationship”, Collegian, Elsevier, Vol. 24 No. 5, pp. 421-425. 